\title{
АНАТОМО-ХИРУРГИЧЕСКИЕ КОРРЕЛЯЦИИ ДОЛЕВОГО СТРОЕНИЯ ПЕЧЕНИ И ЕЕ ИНТРАОРГАННОГО АРТЕРИАЛЬНОГО РУСЛА
}

\author{
(С Тягун В.С. ${ }^{1,2}$, Гайворонский И.В. ${ }^{1}$, Суров Д.А. ${ }^{2,4}$, Анохин Д.Ю. ${ }^{3}$, Ильина В.А. ${ }^{5}$ \\ ${ }^{1}$ Кафедра нормальной анатомии, ${ }^{2}$ кафедра военно-морской хирургии, \\ ${ }^{3}$ кафедра рентгенологии и радиологии (с курсом ультразвуковой диагностики) \\ Военно-медицинской академии имени С.М. Кирова, Санкт-Петербург; ${ }^{4}$ третье хирургическое \\ отделение, ${ }^{5}$ патологоанатомическое отделение Санкт-Петербургского научно-исследовательского \\ института скорой помощи имени И.И. Джанелидзе, Санкт-Петербург \\ E-mail: dr.tyagun@yandex.ru
}

\begin{abstract}
С целью поиска интраорганных артериальных анастомозов изучена артериальная долевая архитектоника, топография истинных междолевых границ печени. Методами препарирования, раздельной инъекции красящих растворов, микрофокусной ангиографии и транспаренхиматозных секций исследованы 23 препарата трупной печени. При инъекции артериального русла печени красящими растворами и рентген-контрастным веществом в 21 случае было отмечено распространение красителя или рентген-контраста только в пределах доли, в которую он вводился. В 2 наблюдениях определялся экстраорганный артериальный анастомоз между ветвями собственной печеночной артерии в воротах печени. На основании результатов исследования установлено, что анатомическое и хирургическое понятия о междолевой границе печени не совпадают по артериальному признаку; макроскопически видимые междолевые интраорганные артериальные анастомозы в норме отсутствуют, что говорит об относительной обособленности долей печени.

Ключевые слова: доля печени, артерии печени, внутрипеченочные артериальные анастомозы, внепеченочные артериальные анастомозы, классификация строения печени, анатомическая номенклатура.
\end{abstract}

\section{ANATOMICO-SURGICAL CORRELATIONS OF THE LOBAR STRUCTURE OF LIVER AND ITS INTRAORGANIC ARTERIAL BED}

Tyagun V.S. ${ }^{1,2}$, Gaivoronskiy I.V. ${ }^{1}$, Surov D.A..$^{2,4}$, Anokhin D.Yu. ${ }^{3}$, Il'ina V.A. ${ }^{5}$

${ }^{1}$ Department of Normal Anatomy, ${ }^{2}$ Department of Naval Surgery, ${ }^{3}$ Department of Radiology

of S.M. Kirov Military Medical Academy, St. Petersburg; ${ }^{4}$ Third Surgical Department; ${ }^{5}$ Department of Pathology

of St. Petersburg I.I. Dzhanelidze Research Institute of Emergency Medicine, St. Petersburg

To reveal the intraorganic arterial anastomoses we studied arterial lobar architectonics and the topography of true hepatic interlobar borders. 23 samples of cadaveric liver were studied with the use of preparating technique, separate injecting colouring solutions, microfocus angiography, and transparenchymal sections. When the arterial bed of the liver was injected with colouring solutions or radiocontrast agents, in 21 cases the agents were visualized only within the injected lobe. In 2 observations, an extraorgan arterial anastomosis was detected between the branches of the hepatic artery in the gates of the liver. The investigation revealed that the anatomical and surgical concepts of the inter-lobar hepatic border do not coincide according to the arterial sign; macroscopically visible inter-lobar intraorganic arterial anastomoses are normally absent, which indicates the relative isolation of hepatic lobes.

Keywords: lobe of the liver, liver arteries, intrahepatic arterial anastomoses, extrahepatic arterial anastomoses, classification of liver structure, anatomical nomenclature.

Традиционно считается, что серповидная связка является междолевой границей печени как наиболее яркий внешний признак. Однако стоит отметить, что еще в 1888 году H. Rех предложил иное описание междолевой границы печени, которая проходит намного латеральнее серповидной связки - от ложа желчного пузыря (ЖП) до нижней полой вены (НПВ). Затем в 1897 (1898) году J. Cantle привел подобное описание указанной границы, выявленной при аутопсии пациента с атрофированной правой долей печени $[1,3,6,0$, 12]. После описания линии Rex-Cantle многие ученые изобретали оригинальные структурные классификации деления печени на доли, пытаясь предложить наиболее верный способ. Изобилие схем в конце концов привело к путанице в клини- ческой практике при необходимости описать границы той или иной доли печени.

Стоит отметить, что представители хирургических школ довольно часто оперируют понятием «линия Rex-Cantle» ввиду необходимости выполнять анатомические резекции печени. Интраоперационно эта линия легко определяется, если произвести временное пережатие одной из долевых артерий, что сказывается на изменении цвета ишемизированной доли $[3,10]$.

По инициативе Всемирной гепато-панкреатобилиарной ассоциации в 2000 году в г. Брисбене (Австралия) на конгрессе была принята международная терминологическая номенклатура анатомии и резекций печени, в основу которой была положена наиболее распространенная классифи- 
кация строения печени по С. Couinaud, основанная на ее сегментарном строении [3]. Основополагающим отличием данного классификационного подхода является разделение печени на две доли, четыре сектора и восемь сегментов по характеру строения воротной системы и венозного оттока. Каждый сегмент имеет автономное питание сосудисто-секреторной ножкой и отделен от соседнего так называемыми малососудистыми зонами. Согласно классификации автора междолевая граница печени в хирургическом плане также представлена линией, соединяющей пузырную вырезку и НПВ (линия Rex-Cantle) и отделяет левый медиальный сектор (представлен IV сегментом, или в классическом описании квадратной долей) от правого медиального (представлен V и VIII сегментами). При этом серповидная связка является границей между медиальным (IV сегмент) и латеральным (II, III сегменты) секторами левой доли [3, 10, 14, 18$]$.

Кроме того, стоит отметить, что в международной анатомической номенклатуре «Terminologia Anatomica» последнего пересмотра конкретной позиции по этому поводу не сформировано, а в своих комментариях анатомическая номенклатурная комиссия допускает дальнейшее обсуждение вопроса о долевом и сегментарном строении печени [5]. Критический анализ доступной литературы показал, что существующие различия заключаются в вопросе, к какой доле печени относить IV сегмент (квадратная доля). В традиционной анатомической классификации его относят к правой доле печени, а по данным клинической практики - к левой доле. Попытки интеграции классической анатомической и «функциональной» классификаций невозможны [14, 18].

Кроме того, с характером классификационного деления долей печени тесно связан вопрос о существовании внутриорганных междолевых артериальных анастомозов, и он до сих пор окончательно не решен [10].

Мельников А.В., Брейтман М.Я., McIndoe A.H. и Counseller V., Ищенко И.Н., Mays Е.Т. на основании отсутствия в печени внутриорганных артериальных анастомозов считают ее двудольным органом [1, 4, 7, 10, 13, 15].

Pack G.T. и др. сообщают, что междолевые интраорганные анастомозы существуют, но в большинстве случаев недостаточны как анатомически, так и функционально. Также обращает на себя внимание описание в доступной литературе, так называемых, участков паренхимы печени с низкой концентрацией сосудистых образований [15].

Segall H.N., Парфентьева В.Ф., Нечунаев Л.М. говорят в пользу существования функционально активных интраорганных междолевых артериаль- ных анастомозов [8, 9, 16].

Достаточно убедительные данные о наличии внепеченочных междолевых сосудистых анастомозов между правой (ПВ) и левой (ЛВ) ветвями собственной печеночной артерии (СПА) приводят Мельников А.B., Tohma Т. [7, 17].

В связи с этим целями нашего исследования явились изучение артериального долевого кровоснабжения, идентификация истинных междолевых границ печени и определение наличия интраорганных артериальных анастомозов.

\section{МАТЕРИАЛЫ И МЕТОДЫ ИССЛЕДОВАНИЯ}

Материалом исследования, проведенного на базе Военно-медицинской академии им. С.М. Кирова и Санкт-Петербургского института скорой помощи им. И.И. Джанелидзе, послужили 23 препарата печени, эксплантированных из небальзамированных трупов мужчин $(n=12)$ и женщин $(\mathrm{n}=11)$, умерших от заболеваний, не связанных с исследуемым органом.

После эксплантации органа, препарировали СПА, ретропеченочный сегмент НПВ и устанавливали перфузионный контур (рис. 1). Последовательно канюлировали (канюли 6-8 Fr, Maquet, Германия) ПВ и ЛВ СПА. Для оттока отработанного перфузата в ретропеченочный сегмент НПВ устанавливали венозную канюлю (24 Fr, Maquet, Германия). Сформированный контур включал в себя роликовый насос с регулятором скорости (ЦНИИ РТК, Россия). Затем, с целью удаления тромботических масс, последовательно отмывали артериальное русло соответствующих долей печени физиологическим раствором в режиме: скорость введения раствора - 350-400 мл/мин, длительность - 20 мин, температура раствора $-37^{0} \mathrm{C}$ ). В конце процедуры в артериальное русло исследуемого органа вводили до 450 мл 4\% раствора цитрата натрия. Всего было проведено 3 серии.

В первой серии исследований проводили инъекции водорастворимых красителей в ПВ $(\mathrm{n}=12)$ и в ЛВ $(\mathrm{n}=11)$ СПА. Инъекции красителей осуществляли болюсно через установленные канюли шприцом объемом 50-150 мл. В качестве красителей использовали для каждой доли печени отдельно разные растворы: 0,05\% бриллиантового зеленого, $1 \%$ сини митиленовой, $0,4 \%$ фуксина основного. Далее производили визуальную оценку зон распространения красителей на поверхности препарата относительно топографии междолевой границы и отмечали особенности расположения последней. 


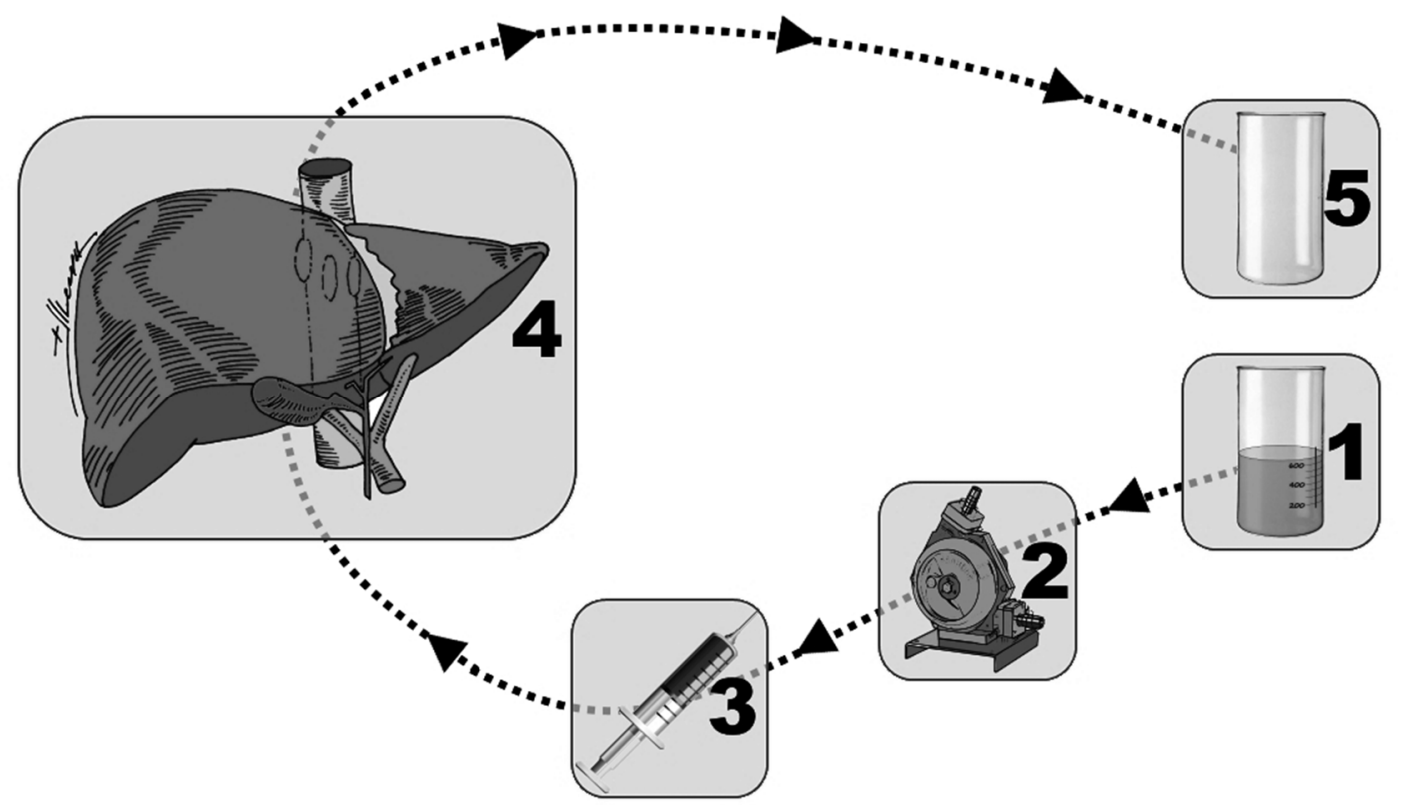

Рис. 1. Схема перфузионного контура для промывания артериального русла. 1 - резервуар с перфузионным раствором; 2 - роликовый насос с регулятором скорости; 3 - переходник для выполнения инъекций красителя; 4 - препарат; 5 - резервуар для сбора отработанного перфузата. Пунктирная линия - направление потока перфузата.

Во второй серии исследований проводили селективную инъекцию ПВ $(\mathrm{n}=5)$ и ЛВ $(\mathrm{n}=4) \mathrm{C}$ ПА рентген-контрастной массой (порошок свинцового сурика и силикон марки СКТН-Б (ГОСТ 1383573) в пропорции 1:20) и с помощью портативного рентгеновского аппарата «ПАРДУС-У» («ЭЛTEX-МЕД», Россия), выполняли микрофокусную ангиографию. Для уточнения топографических особенностей междолевой границы внутри паренхимы и сопоставления результатов первой и второй серий исследований производили предварительную ее маркировку рентген-позитивными объектами.

В третьей серии исследований производили транспаренхиматозные секции через всю толщу препарата в сагиттальном (n=9) и аксиальном $(\mathrm{n}=5)$ направлениях, также визуально оценивали зоны распространения красителей и изучали интраорганную топографию междолевой границы.

\section{РЕЗУЛЬТАТЫ ИССЛЕДОВАНИЯ И ИХ ОБСУЖДЕНИЕ}

В результате проведенной первой серии исследований в 21 случае было отмечено распространение красителя только в пределах доли, в которую он вводился. Наиболее наглядно междолевая граница печени определялась при одновременной инъекции долей печени различными красителями в виде четко выраженного стыка между окрашенными полями (рис. 3a).

Выявленная граница на диафрагмальной поверхности проходила на различных уровнях, на
3,2-6,7 см латеральнее серповидной связки, что противоречит традиционной анатомической классификации. Следует отдельно отметить выявленные различия топографии линии Rex-Cantle. B шести наблюдениях междолевая граница печени проходила на диафрагмальной поверхности от правого края ложа ЖП до правого края НПВ, в четырех - от правого края ложа ЖП до середины НПВ, в шести - от середины ложа ЖП до середины НПВ (n=7) и от левого края ложа ЖП до левого края устья НПВ $(\mathrm{n}=6)$. Аналогичным образом в проекции указанных направлений междолевая граница проходила на висцеральной поверхности печени, косо от вырезки ложа ЖП к вырезке НПВ. При этом, в зависимости от типа кровоснабжения I сегмента печени (хвостатая доля печени), эта линия проходила по его левому краю $(\mathrm{n}=7)$, по середине $(\mathrm{n}=6)$ или по его правому краю $(\mathrm{n}=5)$. Отмечались случаи $(\mathrm{n}=3)$, когда хвостатая доля не окрашивалась, а междолевая граница проходила под ней. Проекция плоскости междолевой границы проходила под углом $57-84^{0}$ по отношению к горизонтальной плоскости. Топография указанной междолевой границы соответствует описанию линии Rex-Cantle на поверхности печени [3, 0, 10, 12, 15].

При анализе данных, полученных в ходе второй серии исследований, в 7 наблюдениях рентген-контрастное вещество распространялось в пределах доли, в которую оно было введено (рис. 2). Высокая плотность и мелкая дисперсность вводимого контраста позволяли детализировать артериальное русло вплоть до терминальных артериальных ветвей. Граница распростране- 
ния контраста в сосудах находилась в \pm 6 мм от промаркированной на поверхности печени выявленной линии Rex-Cantle и не заходила за еe пределы.

В результате проведенной третьей серии исследований - транспаренхиматозными секциями были подтверждены результаты первой и второй серий. Внутри паренхимы междолевая граница продолжалась в проекции левого края или основного ствола средней печеночной вены (рис. 3б). Указанная граница совпадала с принятой по классификации C. Couinaud границей между левой и правой долями или между IV и V, VIII сегментами. Она проходила по середине $(n=7)$, левому $(n=6)$ или правому $(n=10)$ краям средней печеночной вены. При проведении серии транспаренхиматозных секций в сагиттальном направлении перекрестного окрашивания также не наблюда-

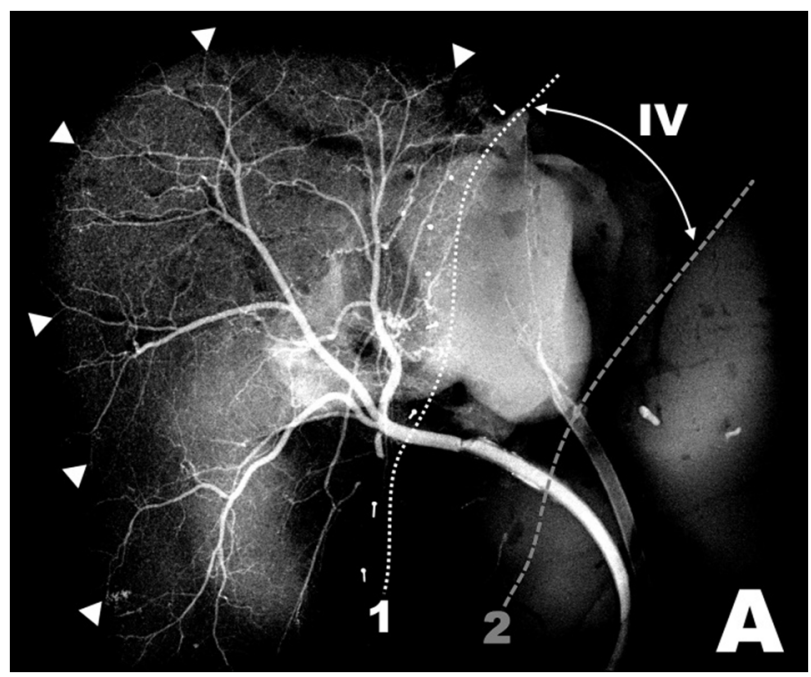

лось. Проекция определенной на поверхности печени линии Rex-Cantle также совпадала и с внутрипеченочной междолевой границей артериальных зон кровоснабжения. Этот факт необходимо учитывать при выполнении хирургических вмешательств и в эксперименте.

В двух наблюдениях в первой серии во время инъекции долей растворами красителей отмечалось окрашивание противоположной доли через экстраорганную ветвь СПА и поверхностное окрашивание участка паренхимы вокруг нее. В этих случаях исследование обязательно продолжалось ангиографией. В ходе дальнейшего препарирования ворот печени с помощью бинокулярной лупы определялась междолевая анастомотическая сеть, образованная мелкими ветвями СПА. Среди указанной сети отмечалась наиболее

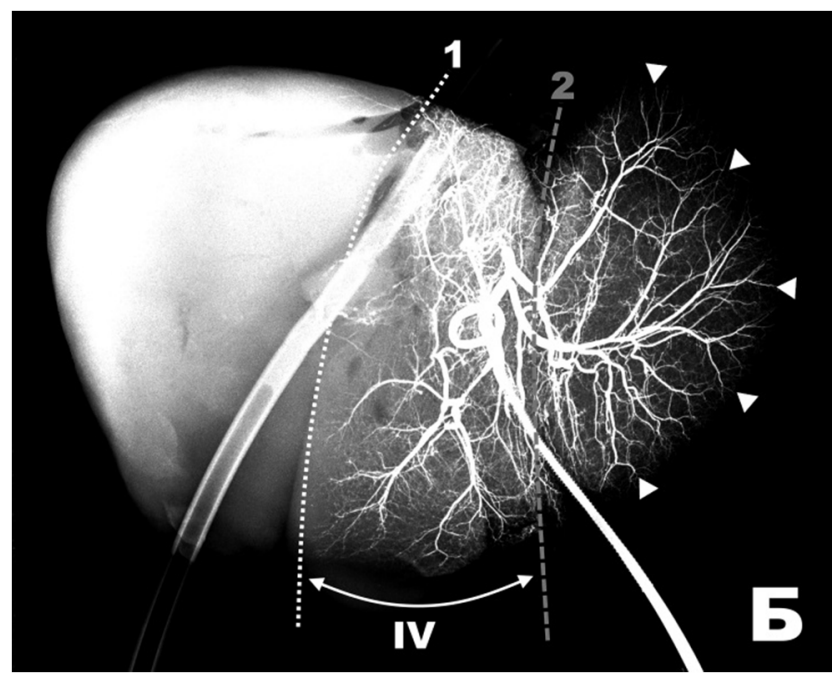

Рис. 2. Долевая артериальная архитектоника печени. Контрастное вещество введено через сосудистую канюлю: А - в ПВ СПА (препарат № 8); Б - в ЛВ СПА (препарат № 10). Обозначения: 1 - пунктирная линия - проекция линии Rex-Cantle (дополнительно промаркирована); 2 - штриховая линия - проекция прикрепления серповидной связки; IV - проекция границ IV сегмента; треугольники - терминальные интраорганные артерии, не анастомозирующие между собой.

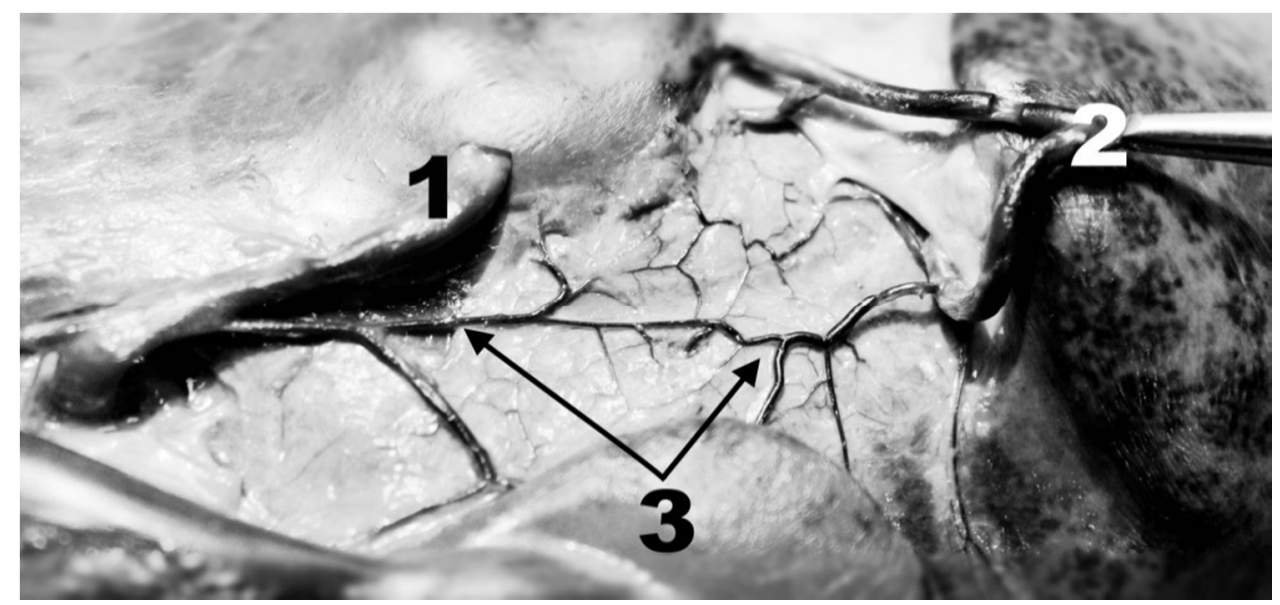

Рис. 4. Фото ворот печени после прецизионного препарирования артерий в бинокулярных лупах. Внепеченочный анастомоз между ветвями СПА, расположенный в капсуле печени. 1 - ПВ СПА; 2 - ЛВ СПА; 3 - внепеченочный анастомоз между ПВ и ЛВ СПА. 

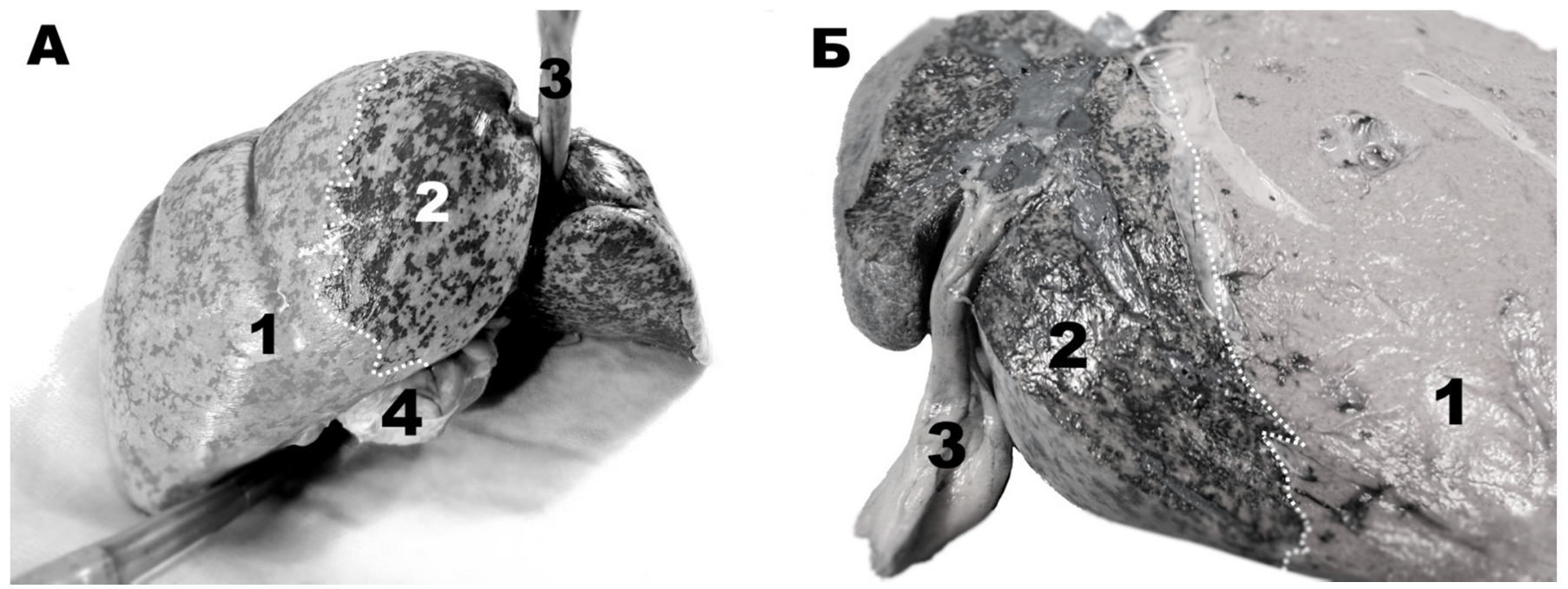

Рис. 3. Топография междолевой границы (линия Rex-Cantle - отмечена пунктирной линией): A - на диафрагмальной поверхности печени; Б - в ее паренхиме (в проекции средней печеночной вены). Препарат № 4. Обозначения: 1 - правая доля; 2 - левая доля; 3 - круглая связка печени; 4 - ЖП.

выраженная аркада диаметром от 1 мм в местах отхождения ветвей СПА и до 0,5 мм в месте слияния образующих ее сосудов (рис. 4). При этом в ходе дальнейшего исследования междолевых интрапеченочных анастомозов выявлено не было, а распространение красителя и рентгенконтрастного вещества отмечалось лишь в поверхностных слоях паренхимы печени вокруг ветви СПА в контралатеральной доле.

Таким образом, на основании полученных результатов исследования можно сделать следующие выводы.

Граница между зонами кровоснабжения долевых ветвей СПА при введении красителей соответствует проекции линии Rex-Cantle, определяемой на поверхности печени, и проходит латеральнее серповидной связки в проекции средней печеночной вены между IV и V, VIII сегментами.

Анатомическое и хирургическое понятия о междолевой границе печени не совпадают: анатомическая междолевая граница определяется по серповидной связке печени, а хирургическая (функциональная) по линии Rex-Cantle.

Указанные различия в определении междолевой границы печени требуют ее унификации и адаптации к условиями клинической практики.

Макроскопически видимые междолевые интраорганные артериальные анастомозы в норме отсутствуют, что говорит об относительной обособленности долевого кровоснабжения.

В 9\% случаев наблюдаются внепеченочные анастомозы между правой и левой ветвями СПА.

Относительная автономность артериальных бассейнов долей печени создает предпосылки к разработке методов изолированной их перфузии.

\section{ЛИТЕРАТУРА / REFERENCES}

1. Борисов А.Е., Земляной В.П., Борисова Н.А., Рыжков В.К., Непомнямая С.Л., Семенов В.А., Рыбкин А.К., Кащуенко В.А., Аяганов С.А., Кубачев К.Г., Левин Л.А., Краснов Л.М. Руководство по хирургии печени и желчевыводящих путей / Под ред. А.Е. Борисова. - СПб. : Предприятие ЭФА, 2002. T. 1. -448 c. [Borisov A.E., Zemlyanoy V.P., Borisova N.A., Ryzhkov V.K., Nepomnyashchaya S.L., Semenov V.A., Rybkin A.K., Kashchenko V.A., Ayaganov S.A., Kubachev K.G., Levin L.A., Krasnov L.M. Guide to surgery of the liver and biliary tract. A.E. Borisov, editor. SPb. : Predpriyatiye EFA. 2002; 1: 448 (in Russ.)].

2. Брейтман М.Я. Анатомические, физиологические и патологические обоснования относительной самостоятельности обоих долей печени, обоих легких и т.д. // Медицинская мысль (научномедицинский журнал). - 1924. - № 1-2. - С. 8-20. [Breytman M.Ya. Anatomical, physiological and pathological rationale for the relative independence of both lobes of the liver, both lungs, etc. Meditsinskaya mysl' (nauchno-meditsinskiy zhurnal). 1924; (1-2): 8-20 (in Russ.)].

3. Гальперин Э.И., Дюжева Т.Г., Ахаладзе Г.Г., Егоров В.И., Жигалова С.Б., Карагюлян С.Р., Котовский С.Б., Мусин Р.А., Чевокин А.Ю., Шериингер А.Г. Лекции по гепатопанкреатобилиарной хирургии: с приложением CD-ROM «Лекции по гепатопанкреатобилиарной хирургии» / под ред. Э.И. Гальперина и Т.Г. Дюжевой. - М. : Видар-М, 2011. - 563 с.: ил. + 1 электрон. опт. диск (CDROM). [Gal'perin E.I., Dyuzheva T.G., Akhaladze G.G., Egorov V.I., ZHigalova S.B., Karagyulyan S.R., Kotovskiy S.B., Musin R.A., Chevokin A.Yu., Shertsinger A.G. Lectures on hepatopancreatobiliary surgery: with the appendix CD-ROM "Lectures on hepatopancreatobiliary surgery". E.I. Gal'perin, T.G. Dyuzheva, editors. M. : Vidar-M; 2011: $563+1$ elektron. opt. disk (CD-ROM). (in Russ.)]. 
4. Ищенко И.Н. Операции на желчных путях и печени. - Киев : Здоров'я, 1966. - 476 с.: ил. [Ishchenko I.N. Surgery on the biliary tract and liver. Kiyev : Zdorov'ya; 1966: 476 (in Russ.)].

5. Колесников Л.Л., Куликов В.В., Асфандиаров Р.И., Баженов Д.В., Бахрушина Л.А., Большаков О.П., Вагапова В.Ш., Каган И.И., Косоуров А.К., Кочетков А.Г., Крылова Н.В., Никитюк Б.А., Самусев Р.П., Сапин М.Р., Соколов В.В., Турыгин В.В., Чернявский М.Н., Черняк И.М., Чучков В.М., Швалев В.Н., Шилкин В.В., Боголепов. Н.Н. Terminologia Anatomica: Международная анатомическая терминология (с официальным списком русских эквивалентов): Пер. с англ. - М. : Медицина, 2003. - 424 c. [Kolesnikov L.L., Kulikov V.V., Asfandiarov R.I., Bazhenov D.V., Bakhrushina L.A., Bol'shakov O.P., Vagapova V.SH., Kagan I.I., Kosourov A.K., Kochetkov A.G., Krylova N.V., Nikityuk B.A., Samusev R.P., Sapin M.R., Sokolov V.V., Turygin V.V., Chernyavskiy M.N., Chernyak I.M., Chuchkov V.M., Shvalev V.N., Shilkin V.V., Bogolepov. N.N. Terminologia Anatomica: International Anatomical Terminology (with official list of Russian equivalents): trans. from English. M. : Meditsina; 2003: 424 (in Russ.)].

6. Литтманн И., Барда Л., Берентеи Д., Боднар Э., Денеш Я., Золтан Я., Маннингер Е., Имре Й., Кеслер П., Лакнер Г., Магаши П., Новак Я. Оперативная хирургия / пер. с венгр.; под ред. М. Алекса [и др.] - Будапешт : Издательство Академии наук Венгрии, 1985. - 1175 с. [Littmann I., Barda L., Berentei D., Bodnar E., Denesh YA., Zoltan YA., Manninger E., Imre Y., Kesler P., Lakner G., Magashi P., Novak Ya. Operational Surgery: trans. from Hungarian; M. Aleks et al., editors. Budapesht : Izdatel'stvo Akademii nauk Vengrii; 1985: 1175 (in Russ.)].

7. Мельников А.В. Об экстраорганных и интраорганных коллатералях // Вестник хирургии. - 1922. T. 2. - C. 373-388. [Mel'nikov A.V. On extraorganic and intraorganic collaterals. Vestnik khirurgii. 1922; 2: 373-388 (in Russ.)].

8. Нечунаев Л.М. Хирургическая анатомия сосудов и желчных протоков печени человека. - Казань : Изд-во Казан. ун-та, 1969. - С. 113-121. [Nechu- nayev L.M. Surgical anatomy of human vessels and bile ducts. Kazan' : Izd-vo Kazan. un-ta; 1969: 113121. (in Russ.)].

9. Парфентьева В.Ф. Архитектоника кровеносных сосудов печени. - Кишинёв : Картя молдовеняскэ, 1960. - C. 75-80. [Parfent'yeva V.F. Architectonics of the blood vessels of the liver. Chisinau: Kartya moldovenyaske; 1960: 75-80 (in Russ.)].

10. Шалимов А.А., Шалимов С.А., Ничитайло М.Е., Доманский Б.В. Хирургия печени и желчевыводящих путей. - Киев : Здоров`я, 1993. - 512 с. [Shalimov A.A., Shalimov S.A., Nichitaylo M.E., Domanskiy B.V. Surgery of the liver and biliary tract. Kiev : Zdorov'ya; 1993: 512 (in Russ.)].

11. Agur A.M.R., Dalley A.F. Grant's atlas of anatomy: $14^{\text {th }}$ edition. - Lippincott Williams \& Wilkins, 2016. $896 \mathrm{p}$.

12. Juza R.M., Pauli E.M. Clinical and surgical anatomy of the liver: A review for clinicians // Clin Anat. 2014. - Vol. 27, N 5. - P. 764-769. - DOI: $10.1002 /$ ca. 22350.

13. Mays E.T., Wheeler C.S. Demonstration of collateral arterial flow after interruption of hepatic arteries in man // N Engl J Med. - 1974. - Vol. 290, N 18. P. 993-996. - DOI: 10.1056/NEJM197405022901804

14. Moore K.L., Dalley A.F., Agur A.M.R. Clinically Oriented Anatomy, $7^{\text {th }}$ Edition. - Baltimore, MD : Lippincott Williams \& Wilkins, 2014. - 1134 p.

15. Pack G.T., Islami A.H., Hamperl H., Higgins G.K., Higginson J., Burdette W.J. Tumors of the Liver. Berlin : Springer-Verlag, 1970. - 306 p.

16. Segall H.N. An experimental anatomical investigation of the blood and bile channels of the liver // Surg Gynecol Obstet. - 1923. - Vol. 37. - C. 152-178.

17. Tohma T., Cho A., Okazumi S., Makino H., Shuto K., Mochiduki R., Matsubara K., Gunji H., Ochiai T. Communicating arcade between the right and left hepatic arteries: evaluation with $\mathrm{CT}$ and angiography during temporary balloon occlusion of the right or left hepatic artery // Radiology. - 2005. - Vol. 237, N 1 P. 361-365. - DOI: 10.1148/radiol.2371040919.

18. Trauma, $6^{\text {th }}$ Edition. / D.V. Feliciano, K.L. Mattox, E.E. Moore, editors. - McGraw-Hill Professional, 2008. $-1430 \mathrm{p}$. 